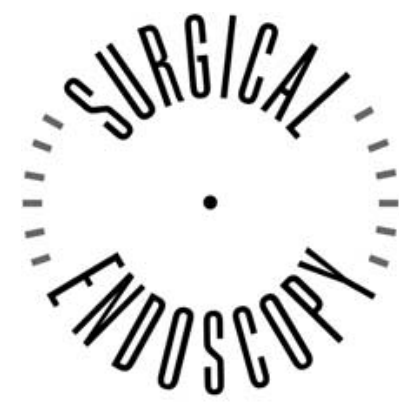

and Other Interventional Techniques

\title{
Early peritoneal macrophage function after laparoscopic surgery compared with laparotomy in a mouse model
}

\author{
U. Moehrlen, ${ }^{1}$ F. Schwoebel, ${ }^{2}$ E. Reichmann, ${ }^{1}$ U. Stauffer, ${ }^{1}$ C. A. Gitzelmann, ${ }^{1,4}$ J. Hamacher ${ }^{2,3,4}$ \\ ${ }_{2}^{1}$ Department of Pediatric Surgery, University Children's Hospital, Steinwiesstrasse 75, Zurich, CH-8032, Switzerland \\ ${ }^{2}$ Faculty of Biology, University of Konstanz, Post Office Box M668, Konstanz, D-78457, Germany \\ ${ }^{3}$ Internal Medicine V/Pulmonary Division, University Hospital of Homburg/Saar D-66421, Homburg \\ ${ }^{4}$ Both authors contributed equally to the work
}

[Surg Endosc (2005) 19: 958-963, DOI: 10.1007/s00464004-2118-2]

F. Schwoebel's name was misspelled in the published version of this article. In addition, the notifica- tion "C. A. Gitzelmann and J. Hamacher both contributed equally to the work" was inadvertently omitted from the title page of the article. The publisher regrets the error. 